\title{
Suicidal atferd ved ustabil personlighetsforstyrrelse
}

\author{
Ved Lars Mehlum og Anne Irene Jensen
}

Artikkelen ble første gang publisert i Tidsskrift for Den norske lægeforening 2006, 126, 9: 2946-9. Oppgitte interessekonflikter: Ingen

Pasienter med ustabil personlighetsforstyrrelse har betydelig overhyppighet av selvskadende og suicidal atferd og det oppleves ofte vanskelig å gi dem effektiv behandling. Sterk overfølsomhet for negative livshendelser, affektlabilitet og impulsivitet er blant de faktorene som øker risikoen for repeterende suicidalkriser. Det er viktig at klinikere bruker nødvendig tid til å gjøre individ- og situasjonsspesifikke vurderinger av selvmordsrisikoen. Dersom risikoen er høy, kan det være aktuelt med kortvarig døgnbehandling som kriseintervensjon. For $\emptyset$ vrig vil de fleste pasientene trenge spesialtilpassede og lengrevarende behandlingsopplegg fremfor stadig skiftende terapeutiske opplegg som trolig vil forverre prognosen. Det finnes flere ulike modeller for behandling tilgjengelig, bl.a. dialektisk atferdsterapi og mentaliseringsbasert terapi. Vi drøfter hvordan man i disse behandlingsformene forholder seg til pasientenes tendens til selvskadende og suicidal atferd og hvilke resultater som hittil er blitt oppnådd i studier av behandlingseffekter.

Selvskadende og suicidal atferd er velkjente og vanskelige utfordringer for mange klinikere som behandler pasienter med ICD-10-diagnosen "emosjonelt ustabil personlighetsforstyrrelse" - svarende til "borderline personlighetsforstyrrelse" i det amerikanske diagnosesystemet DSMIV (1). Tilstanden kjennetegnes av vansker med affektregulering og impulskontroll og av et betydelig varierende selvbilde og ustabilitet i forholdet til andre mennesker.

Studier har vist at pasienter med denne diagnosen har 10-15 ganger høyere selvmordsrisiko enn normalbefolkningen; en risiko på samme høye nivå som den hos mennesker med alvorlige stemningslidelser (2-5). Ikke sjelden undervurderes selvmordsrisikoen fordi pasientene også har betydelig $\varnothing \mathrm{kt}$ tendens til selvdestruktiv atferd med liten eller ingen suicidal intensjon (6), bl.a. ulike former for selvskading (7), slik som selvpåført risping, kutting, brenning, eller forgiftning med alkohol, medikamenter og illegale rusmidler. Overgangen mellom suicidalt og ikke-suicidalt motiverte handlinger er flytende.

For å kunne tilby riktig behandling, er det nødvendig med en systematisk og nøktern vurdering av hvor alvorlig selvmordsatferden hos den enkelte pasient er i den aktuelle situasjonen. Vår erfaring er at selvmordstrusler og selvmordsatferd hos pasienter med ustabil personlighetsforstyrrelse kan oppleves som svært stressende for behandlere, og både sinne, angst og hjelpeløshet kan vekkes. Vi kan ikke se bort fra at slike reaksjoner hos behandlerne kan medføre fare for at det fattes irrasjonelle beslutninger og gis ineffektiv behandling. På bakgrunn av disse kliniske utfordringene og gjennom $\varnothing$ kt kunnskap om ustabil personlighetsforstyrrelse, har man de siste årene utviklet nye behand- lingsmodeller som er blitt vitenskapelig evaluert. I denne artikkelen gjør vi rede for noen av de forholdene som disponerer for suicidalitet hos pasienter med ustabil personlighetsforstyrrelse, og dernest gis en oversikt over aktuelle psykososiale behandlingsmetoder.

\section{Affektlabilitet og impulsivitet}

Personer med ustabil personlighetsforstyrrelse har ofte sterk overfølsomhet for negative livshendelser, særlig i mellommenneskelige forhold, slik som ved relasjonsbrudd eller konflikter, og de opplever ofte betydelig symptomforverring under stress. De følelsesmessige reaksjonene kommer raskere og er gjerne sterkere enn hos andre, og det tar lengre tid å vende tilbake til et nøytralt stemningsleie (8). Denne affektlabiliteten bidrar til å $\varnothing \mathrm{ke}$ risikoen for selvmordsatferd (4). Det samme gjelder impulsivitet - et personlighetstrekk som predikerer selvmordsatferd ved en rekke psykiske lidelser (9-10), men som er fremtredende ved ustabil personlighetsforstyrrelse og et av de diagnostiske kriteriene ved borderline personlighetsforstyrrelse. Biologiske studier tyder på at impulsiv suicidal atferd er assosiert med forstyrrelser i serotonerge nervebaner i hjernen (11) uten at de eksakte årsaksmekanismene er kjent. Individer med utpreget impulsivitet ser ut til å være mer sårbare for at negative livshendelser og stress skal utløse en selvmordskrise.

I klinisk sammenheng er sannsynligvis selvdestruktiv impulsivitet den st $\varnothing$ rste utfordringen pasienter med ustabil personlighetsforstyrrelse byr sine behandlere, fordi dette personlighetstrekket kan være livstruende og fordi det kan skape alvorlige vansker for pasientenes evne til å nyttiggjøre seg behandling. Dette er årsaken til at flere aktuelle behandlings- modeller for ustabil personlighetsforstyrrelse så sterkt, i et tidlig stadium, sikter mot å kunne romme og kontrollere selvdestruktive impulser og sterke affekter. Klinikere bør vurdere nøye hvordan de systematisk kan behandle impulsivitet både psykoterapeutisk og farmakologisk hos den enkelte pasient. Dette vil sannsynligvis medføre en reduksjon av selvmordsatferd hos denne pasientgruppen.

\section{Komorbiditet}

Ustabil personlighetsforstyrrelse har utstrakt komorbiditet med andre psykiske lidelser, særlig stemningslidelser, angstlidelser og rusmisbruk, og flere studier har vist at slik komorbiditet $\varnothing$ ker risikoen for suicidal atferd $(3,12-14)$. Dette er

\section{Hovedbudskap}

- Personer med ustabil personlighetsforstyrrelse har $\emptyset \mathrm{kt}$ risiko for suicidal og annen selvskadende atferd og pasientene oppleves ofte som vanskelige å behandle.

- Suicidalkriser forekommer hyppig og krever individ- og situasjonsspesifikke vurderinger av selvmordsrisiko.

- Spesialtilpassede lengrevarende behandlingsopplegg er å foretrekke fremfor serier med kortere intervensjoner.

- Dialektisk atferdsterapi og mentaliseringsterapi er effektivt med henblikk på å redusere suicidal atferd i denne pasientgruppen. 
ikke uventet, siden komorbiditet kompliserer de kliniske tilstandene og gjør dem dermed vanskeligere å vurdere og behandle.

For pasienten medfører komorbiditet også en større samlet symptombelastning. Situasjonen krever integrerte behandlingsmodeller der flere ulike behandlingsinstanser blir involvert. Men i virkeligheten er det heller sjelden at pasienter med personlighetsforstyrrelser i selvmordskrise får et slikt integrert tilbud (15).

\section{Vurdering av selvmordsrisiko}

Noen klinikere mener at selvmordsatferd hos pasienter med ustabil personlighetsforstyrrelse egentlig gjenspeiler en måte å kommunisere på uten at det dreier seg om noe egentlig dødsønske. Dette st $\varnothing t t e s$ ikke av empirisk forskning som tvert imot har vist at disse pasientene har like høy grad av selvmordshensikt og dødelighet knyttet til selvmordsfors $\varnothing \mathbf{k}$ som andre suicidale pasientgrupper (15, 16). Det er imidlertid viktig å skille mellom passive $d \varnothing d s \varnothing n s k e r$ og tanker om selvmord som erfaringsmessig mange pasienter med ustabil personlighetsforstyrrelse bærer på mye av tiden (17), på den ene siden og aktive selvmordstanker og planer og aktuelle suicidalfors $\varnothing \mathrm{k}$ på den andre. Her er det naturligvis ingen skarpe skiller. Aktuelle selvmordstanker og -handlinger må derfor vurderes grundig $i$ henhold til vanlige prinsipper for risikovurdering (18). Enkelte klinikere har dessverre tendens til å gå fort lei av å foreta gjentatte vurderinger av selvmordsrisiko hos pasienter med kronisk hang til slik atferd, og ignorerer eller bagatelliserer pasientens utsagn om selvmord.

Denne strategien er ikke å anbefale. Det er påkrevd å gjøre fortløpende risikovurderinger.

\section{Kriseintervensjon}

Pasienter med ustabil personlighetsforstyrrelse er ofte å se på legevakter og i sykehusenes akuttmottak. Det er en stor utfordring å sikre dem krisehjelp og behandling som reduserer risikoen for suicidal atferd både på kort og lang sikt. Det er dessverre grunn til å uroe seg over at visse aspekter av vår kriserespons til disse pasientene kan ha negative langsiktige virkninger $(19,20)$. Dersom pasienter opp- lever at klinikerne bare responderer på deres rop om hjelp eller rop av smerte når temaet selvmord bringes på bane, er det naturligvis egnet til å forsterke tendensen til suicidal atferd. Kliniske erfaringer tyder også på at disse pasientene er meget sårbare for hyppig skifte av behandlere (19).

\section{Innleggelse?}

En av de mest problematiske og risikofylte avgjørelser klinikeren står overfor $i$ håndteringen av selvmordskriser hos disse pasientene, er spørsmålet om innleggelse. Det kan være en reell risiko for at pasienten - dersom hun ikke beskyttes i sykehusomgivelser - kan komme til å ta sitt eget liv eller påføre seg irreversibel skade. Men innleggelse er heller ikke uten risiko. Ikke sjelden kan pasienter med ustabil personlighetsforstyrrelse faktisk oppleve symptomforverring etter noen dagers døgnopphold i psykiatrisk akuttavdeling i form av psykosenær dekompensering eller gjennom sin tendens til raskt å bli involvert i negative samspill med personale eller medpasienter. Resultatet kan bli en $\varnothing$ kning i selvmordstrusler, selvskading eller selvmordsatferd som igjen kan medføre forlenget innleggelse, eller hva verre er, fremprovosere for tidlig utskrivning eller andre negative reaksjoner fra sykehuspersonalet. Det er derfor vektige grunner til å søke å unngå d $\varnothing g$ ninnleggelse. Hvis behovet for beskyttelse likevel gjør innleggelse uunngåelig, bør den være av kort varighet og det kan i visse tilfeller være hensiktsmessig å avtale en dato for utskrivning på forhånd. Dette må naturligvis pasienten være innforstått med. Hospitalsbehandling av pasienter med ustabil personlighetsforstyrrelse $b \varnothing r$ fortrinnsvis skje i form av dagbehandling i enheter som har et behandlingsopplegg spesielt tilpasset denne pasientgruppen.

\section{Spesialiserte behandlingsprogrammer}

Til tross for at sykehusinnleggelse av pasienter med ustabil personlighetsforstyrrelse har flere problematiske sider, har disse pasientene ofte behov for mer struktur og beskyttelse enn hva en poliklinikk kan tilby. Dette har ført til utvikling av flere typer strukturerte og intensive behandlingsformer. Vi skal her kon- sentrere oppmerksomheten om de to psykoterapeutiske behandlingsmetodene som hittil har vist seg å ha forebyggende effekt på suicidal atferd hos pasienter med ustabil personlighetsforstyrrelse. Disse behandlingsmetodene er nå i ferd med å vinne innpass også i norsk psykisk helsevern.

\section{Dialektisk atferdsterapi}

Dialektisk atferdsterapi (dialectical behaviour therapy - DBT) ble utviklet av den amerikanske psykologen Marsha M. Linehan som behandlingsmetode for suicidale kvinner med borderline personlighetsforstyrrelse (21). Denne behandlingen integrerer velprøvde teknikker fra kognitiv terapi og atferdsterapi med utgangspunkt i Linehans biososiale teori om borderlinesyndromet (8). Gjennom ukentlig individualterapi og gruppeterapi samt hjemmearbeid arbeides det systematisk med å redusere den affektive instabiliteten som er så typisk for borderlinepasienter. Sentralt står også målet om å redusere suicidal og/eller terapihemmende atferd. Det forventes at pasienter kontakter sin individualterapeut før de ev. handler på suicidale impulser som med stor sannsynlighet vil komme. Dette gjør det påkrevd at pasientene får mulighet til å ta telefonkontakt med sin terapeut også utenom kontortiden. Hensikten med dette er at pasientene skal få hjelp til å fastholde og anvende ferdighetene de har lært når det dukker opp vanskelige situasjoner. Samtidig får pasientene trening $\mathrm{i} a ̊$ ta kontakt i tidligere stadier av sin krise, der terapeuten faktisk kan være til nytte med å finne alternative løsninger. Det legges derfor mye vekt på å forsterke all atferd som er konstruktiv og problemløsende fremfor atferd som er suicidal og destruktiv. Dermed blir det viktig at terapeuten gir pasienten (minst) like mye oppmerksomhet når pasienten ringer for å snakke om mindre krisepregede ting, som når pasienten ringer for å snakke om planer om å skade seg selv.

Dialektisk atferdsterapi deles inn i fire stadier. Det er likevel stadium 1 der primærmålet er å stabilisere pasienten og hjelpe henne til å få kontroll over suicidalatferden sin, som naturlig nok har fått st $\varnothing$ rst oppmerksomhet og anvendelse i kliniske settinger de fleste steder. 
Målsettingen i dette behandlingsstadiet oppnås gjennom systematisk arbeid med å styrke sosiale ferdigheter, følelsesregulering og selvstyring, gi $\varnothing \mathrm{kt}$ toleranse for ubehagelige følelser og gi en bedret refleksjonsevne. I senere stadier av behandlingen rettes oppmerksomheten mot problemer og symptomer relatert til tidligere traumer som mange pasienter med repeterende suicidal atferd sliter med (22).

I behandlingens første stadium, som kan vare opptil ett år, holdes et betydelig fokus på suicidal og/eller terapihemmende atferd. Pasienten fyller daglig ut kort der informasjon om selvmordstanker, impulser og handlinger registreres. Kortene samles inn ved starten av hver individualterapitime og gjennomgås sammen med behandleren. Dersom pasienten rapporterer suicidal atferd, blir dette nøye kartlagt i timen og terapeuten gjør også en vurdering av d $\varnothing$ dsrisiko i forhold til den rapporterte handlingen. Så følger en såkalt kjedeanalyse, der de ulike stadiene i hendelsesforløpet som ledet frem til den selvdestruktive handlingen blir unders $\varnothing \mathrm{kt}$. Hvilken følelsesmessige tilstand befant pasienten seg i da prosessen startet? Hva fungerte som utløsere? Hvordan reagerte, følte og tenkte pasienten i de ulike stadiene og hva var konsekvenser av handlingen? Hvordan virket det inn på andre? Hvilke alternative måter kunne pasienten brukt for å løse sine problemer? De fleste selvdestruktive handlinger representerer pasientens fors $\varnothing \mathrm{k}$ på å løse mellommenneskelige eller følelsesmessige problemer, og målet med kjedeanalysene er å $\varnothing \mathrm{ke}$ pasientens oppmerksomhet på hva som skjer slik at hun kan bli i stand til å velge mer konstruktive løsninger.

Naturligvis oppstår suicidalkriser underveis i behandlingen. I slike situasjoner gjøres, etter vanlige prinsipper, vurdering av den aktuelle risiko og det iverksettes intervensjoner i henhold til dette. Dette kan innebære å fjerne potensielt giftige medikamenter, skytevåpen eller alkohol slik at faren for impulsive selvmord reduseres. Siden pasienten faktisk befinner seg i et intensivt behandlingsopplegg rettet mot selvmordsatferd og med atskillig terapeutisk st $\varnothing$ tte, anses vanligvis behovet for døgnhospitalisering å være mindre. Men i noen tilfeller kan en kortvarig innleggelse ikke unngås, og da bør en minst mulig invaderende løsning velges.
Det er krevende å arbeide med pasienter som har så vidt omfattende og til tider livstruende problemer. Det er derfor av særlig interesse at dialektisk atferdsterapi inkluderer systematisk faglig st $\varnothing$ tte til behandlerne. Det kreves at behandlere arbeider i team og at det gis veiledning og kollegial st $\varnothing$ tte som et ledd i å opprettholde tilstrekkelig kvalitet på behandlingen og å unngå utbrenthet og andre psykiske helseskader hos personalet (8).

Effekten av dialektisk atferdsterapi har blitt studert i flere randomiserte, kontrollerte studier. Den første var Linehans mye siterte studie fra 1991 der hun viste at denne behandlingen ga signifikant færre selvmordsfors $\varnothing \mathrm{k}$ og episoder med selvskading enn vanlig terapi de første seks måneder etter fullført behandling (21). Det var også betydelig færre av dem som fikk dialektisk atferdsterapi som droppet ut fra behandlingen, og antallet liggedager i sykehus ble redusert. Etter 12 måneder viste det seg imidlertid at selv om pasientene i gruppen som fikk dialektisk atferdsterapi fortsatt systematisk gjorde det bedre enn pasientene som fikk vanlig behandling, var det ikke lenger signifikante forskjeller når det gjaldt suicidal atferd (23). I de senere år har flere andre forskergrupper både i USA og Europa studert effekten av dialektisk atferdsterapi på suicidal atferd og fătt gode resultater $(24,25)$. Et problem ved flere av studiene har imidlertid vært at pasienttallet har vært forholdsvis beskjedent, at man har utelukket pasienter med flere diagnoser enn borderline personlighetsforstyrrelse og at man primært har inkludert pasienter med et $m \varnothing n s t e r$ av repeterende suicidalitet. Dette er forhold som bør føre til varsomhet i forhold til å generalisere funnene til alle pasienter med borderline personlighetsforstyrrelse. Vi vet ikke om dette primært er en terapi for kronisk suicidale pasienter. Dialektisk atferdsterapi er for tiden i bruk overfor stadig flere pasientgrupper med og uten suicidal atferd, og tiden vil vise hvilke anvendelsesområder vi blir stående igjen med. Behandlingen i de senere år er også blitt tilpasset for ungdommer med repeterende suicidal atferd $(26,27)$, men ingen effektstudier er hittil utf $\varnothing$ rt.

\section{Mentaliseringsbasert terapi}

Mentaliseringsterapi eller mentaliseringsbasert terapi (MBT) er en psykoana- lytisk orientert behandlingsform utviklet av britene Anthony Bateman \& Peter Fonagy. Behandlingen har som mål å hjelpe pasienten til å oppnå bedre affektkontroll og lære mer hensiktsmessige affektuttrykk og samtidig få styrket evnen til å inngå i trygge og gode relasjoner til andre mennesker (28). Et sentralt begrep i behandlingsmodellen er mentalisering. Utviklingspsykologisk tenker vi oss at barn normalt oppøver evnen til mentalisering gjennom den trygge tilknytningen til og lekende samspillet med foreldrene der tanker og følelser, $\varnothing$ nsker og antakelser kan oppleves av barnet som betydningsfulle og viktige indre representasjoner, og disse er forbundet med, men likevel atskilt fra, den ytre virkeligheten (29). Mentaliseringen fører til en opplevelse av sammenheng mellom indre og ytre realiteter og til utvikling av et sammenhengende selv som kan være i meningsfylt samspill med andre mennesker. I mentalisering ligger evnen til å kunne tenke om egen og andres tenkning, kunne stå utenfor egne følelser og observere egne og andres følelser, noe som er viktig for å kunne se en sak fra flere sider, forstå hvordan andre tenker og føler og kunne mestre egne følelsesmessige reaksjoner. Denne evnen er imidlertid svakt utviklet hos personer med ustabil personlighetsforstyrrelse. Gjennom mentaliseringsbasert terapi vil pasienten med basis i en trygg (nok) tilknytning til terapeuten få anledning til åpent å utforske den andres sinn, for så å finne sitt eget sinn representert i den andres sinn, som Bateman \& Fonagy uttrykker det (30). Slik kan pasienten oppnå en bedre evne til mentalisering og derigjennom bedre evne til affektkontroll og mestring av relasjoner til andre mennesker.

Mentaliseringsbasert terapi gjennomføres typisk sett i individual- og gruppesammenheng og gjerne i en dagavdeling, siden dette hjelper pasientene til å opprettholde autonomi og forebygger tendensen til regresjon (29). Man forholder seg aktivt til pasienters eventuelle akutte og kronisk tilstedeværende selvmordsrisiko bl.a. gjennom at behandlerteamet samarbeider tett om dette utfordrende spørsmålet i forhold til den enkelte pasient. Man er generelt tilbakeholden med sykehusinnleggelser, som ikke anses å virke gunstig inn på den kroniske selv- 
mordsrisikoen. Ved akutt forverring av selvmordsrisiko kan det imidlertid være aktuelt med kortvarig sykehusinnleggelse, og det bør da være klart definerte mål for oppholdet, som bør være frivillig og $\varnothing$ nsket av pasienten. Oppholdet bør ikke vare mer enn noen få dager, og utskrivningsdato bør være planlagt på forhånd. Også i mentaliseringsbasert terapi anser man det som svært sentralt å bearbeide selvmordstrusler og -kriser på en aktiv måte i behandlingen. Disse kan bringe behandleren ut av fatning og resultere i destruktive motoverføringer og projeksjoner fra behandlerens side og dermed hemme arbeidet med å styrke pasientens evne til mentalisering. Behandleren må naturligvis sørge for at det gjøres en systematisk vurdering av suicidalfaren, og da helst foretatt av et annet medlem av behandlerteamet, og deretter iverksette adekvate beskyttelsestiltak. Begrunnelsen for å bruke et annet teammedlem enn behandleren, er å minimere den gevinsten pasienten kan oppleve ved å få ekstra oppmerksomhet fra og hyppigere kontakt med behandleren. Man er opptatt av at suicidalitet ikke skal være den valuta som brukes til å kjøpe ekstra omsorg og oppmerksomhet. I stedet bør suicidaltanker tas opp som tema under den vanlige, løpende behandlingen i individual-og gruppesammenheng. Utenom kontortiden har pasienten anledning til å ringe behandlingsenheten ved kriser og vil i slike tilfeller få råd om hvordan situasjonen kan håndteres.

Studier har vist at mentaliseringsbasert terapi er en effektiv behandling i forhold til suicidal atferd hos pasienter med ustabil personlighetsforstyrrelse. En unders $\varnothing$ kelse av Bateman \& Fonagy viste at metoden ga færre selvmordsfors $\varnothing \mathrm{k}$, mindre selvskading, færre innleggelser i sengeavdeling, mindre angst og depresjon og bedre sosial tilpasning enn tradisjonell behandling. De samme forskerne har også vist at denne behandlingsformen er $\varnothing$ konomisk konkurransedyktig i forhold til vanlig psykiatrisk behandling (31).

\section{Norsk behandlingshverdag}

Det er liten tvil om at det også her til lands er et stort behov for den typen behandlingsmetoder som vi har skissert. Det finnes flere modeller i bruk, men trolig er det de to modellene vi har nevnt her som har størst mulighet til å vinne frem i norsk behandlingshverdag. Det sterke fagmiljøet omkring Avdeling for personlighetspsykiatri ved Ullevål universitetssykehus i Oslo og, fra 1993, et nettverk av samarbeidende psykoterapeutiske dagavdelinger i ulike deler av landet for $\varnothing v$ rig, har utviklet en analytisk orientert gruppepsykoterapi for dårlig fungerende pasienter med personlighetsforstyrrelser. Der har man fått noen av de samme positive resultatene med kombinasjon av dagbehandling og poliklinisk oppfølging som rapportert av Bateman $\&$ Fonagy. Dagavdelingsbehandlingen ved Ullevål bygger på et solid lokalt utviklingsarbeid, men har også hentet inspirasjon bl.a. fra mentaliseringsbasert terapi. For tiden pågår en randomisert, kontrollert studie av effekter av denne behandlingen.

Også dialektisk atferdsterapi er på vei inn i norske behandlingsenheter, særlig i barne- og ungdomspsykiatrien flere steder i landet. Læreb $\varnothing$ ker i behandlingsmetoden er kommet også på norsk (32), og det er i ferd med å bli igangsatt systematiske terapeututdanningsopplegg. Ved Seksjon for selvmordsforskning og -forebygging, Universitetet i Oslo i samarbeid med andre forskningsmiljøer og helseforetak, er en randomisert, kontrollert multisenterstudie av dialektisk atferdsterapi tilpasset for ungdommer med repeterende suicidal atferd under oppstart (33).

En styrke ved de nevnte behandlingsmetodene ser ut til å være at de i st $\varnothing r r e$ grad enn andre metoder, og ikke minst i forhold til vanlig behandlingspraksis overfor pasienter med ustabil personlighetsforstyrrelse, forholder seg til pasientene som de faktisk er og tilbyr en behandling som de i utgangspunktet har forutsetninger for å kunne nyttiggjøre seg. I en tankevekkende artikkel av Fonagy \& Bateman pekes det på at den dårlige prognosen vi har vært vant til å tilskrive pasienter med ustabil personlighetsforstyrrelse kanskje delvis er iatrogen (19). Altfor mange av disse pasientene opplever nemlig stadige terapeutskifter og avbrudd i behandlingsopplegg, noe som trolig er assosiert med en slett prognose. Det pasientene imidlertid trenger, er behandlingsopplegg som forholder seg til deres grunnleggende problemer med tilknytning og mestring av nære mellommenneskelige relasjoner.

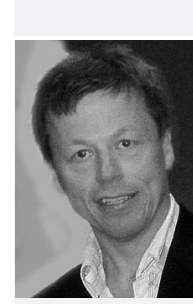

Lars Mehlum

er psykiater og professor i suicidologi ved Univ. i Oslo. Han er leder for SSFF og er bredt engasjert i en rekke forsknings- og forebyggingsprosjekter. Han har publisert flere læreb $\varnothing$ ker, samt en rekke vitenskapelige artikler.

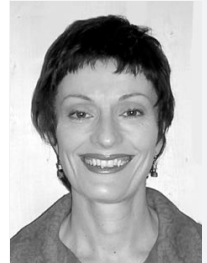

Anne Irene Jensen er psykiater og har tatt videreutdanning i selvmordsforebyggende arbeid ved $\mathrm{UiO}$. I den forbindelse fordypet hun seg i temaet borderline personlighetsforstyrrelse og suicidalitet. Hun jobber som stipendiat ved Avdeling for forskning og under visning på Diakonhjemmet sykehus i TOPprosjektet (Tematisk Område Psykose).

1. januar 2007 begynner hun som avdelingsoverlege ved Folloklinikken.

\section{Litteratur}

1. Diagnostic and statistical manual of mental disorders DSM-IV. 4. utg. Washington D.C:

American Psychiatric Association, 1994.

2. Baxter D, Appleby L. Case register study of suicide risk in mental disorders. Br J Psychiatry 1999; 175: 322-6.

3. Foster T, Gillespie K, McClelland R et al. Risk factors for suicide independent of DSM-III-R axis I disorder: case-control psychological autopsy study in Northern Ireland. Br J Psychiatry 1999; 175: $175-9$

4. Linehan MM, Rizvi SL, Welch SS et al. Psychiatric aspects of suicidal behaviour: personality disorders. I: Hawton K, van Heeringen K, red. The international handbook of suicide and attempted suicide. Chichester: John Wiley, 2000.

5. Cheng AT, Chen TH, Chen CC et al. Psychosocial and psychiatric risk factors for suicide: case-control psychological autopsy study. $\mathrm{Br} J$ Psychiatry 2000; 177: 360-5.

6. Stanley B, Gameroff MJ, Michalsen V et al. Are suicide attempters who self-mutilate a unique population? Am J Psychiatry 2001; 158: 427-32.

7. Gunderson JG, Ridolfi ME. Borderline personality disorder: suicidality and self-mutilation. Ann NY Acad Sci 2001; 932: 61-77.

8. Linehan M. Understanding borderline personality disorder: the dialectical approach. New York: Guilford Publications, 2001.

9. Mann JJ, Waternaux CHGL, Malone KM. Toward a clinical model of suicidal behavior in psychiatric patients. Am J Psychiatry 1999; 156 : 181-9.

10. Soloff PH, Lynch KG, Kelly TM et al. Characteristics of suicide attempts of patients with major depressive episode and borderline personality disorder: a comparative study. Am J Psychiatry 2000; 157: 601-8. 
(Forts. fra s. 20 - Suicidal atferd ved ustabil personlighetsforstyrrelse)

11. Oquendo M, Mann JJ. The biology of impulsivity and suicidality. Psychiatr Clin North Am 2000; 23: 11-25.

12. Beautrais AL, Joyce PR, Mulder RT et al. Prevalence and comorbidity of mental disorders in persons making serious suicide attempts: a case-control study. Am J Psychiatry 1996; 153: 1009-14.

13. Corbitt EM, Malone KM, Haas GL et al. Suicidal behavior in patients with major depression and comorbid personality disorders. J Affect Disord 1996; 20: 61-72.

14. Ferreira de Castro E, Cunha MA, Pimenta F et al. Parasuicide and mental disorders. Acta Psychiatr Scand 1998; 97: 25-31.

15. Suominen KH, Isometsa ET, Henriksson MM et al. Suicide attempts and personality disorder. Acta Psychiatr Scand 2000; 102: 118-25.

16. Soloff PH, Fabio A, Kelly TM et al. High-lethality status in patients with borderline personality disorder. J Personal Disord 2005; 19: 386-99.

17. Mehlum L, Friis S, Vaglum P et al. The longitudinal pattern of suicidal behaviour in borderline personality disorder: a prospective follow-up study. Acta Psychiatr Scand 1994; 90: 124-30.

18. Mehlum L. Tilbake til livet: selvmordsforebygging i teori og praksis. Kristiansand: Høyskoleforlaget, 1999: 141-56.

19. Fonagy P, Bateman A. Progress in the treatment of borderline personality disorder. Br J Psychiatry 2006; 188: 1-3.

20. Paris J. Chronic suicidality among patients with borderline personality disorder. Psychiatr Serv 2002; 53: 738-42.

21. Linehan MM, Armstrong HE, Suarez A et al. Cognitive behavioral treatment of chronically parasuicidal borderline patients. Arch Gen Psychiatry 1991; 48: 1060-4.

22. Mehlum L. Traumatic stress and suicidal behaviour: an important target for treatment and prevention. I: Hawton K, red. Prevention and treatment of suicidal behaviours: from science to practice. Oxford: Oxford University Press, 2005: 121-38.
23. Linehan MM, Heard HL, Armstrong HE et al. Naturalistic follow-up of a behavioral treatment for chronically parasuicidal borderline patients. Arch Gen Psychiatry 1993; 50: 971-4.

24. Koons CR, Robins CJ, Tweed JL et al. Efficacy of dialectical behavior therapy in women veterans with borderline personality disorder. Behav Therapy 2001; 32: 371-90.

25. Verheul R, Van Den Bosch LM, Koeter MW et al. Dialectical behaviour therapy for women with borderline personality disorder: 12-month, randomised clinical trial in The Netherlands. Br J Psychiatry 2003; 182: 135-40.

26. Katz LY, Cox BJ, Gunasekara S et al. Feasibility of dialectical behavior therapy for suicidal adolescent inpatients. J Am Acad Child Adolesc Psychiatry 2004; 43: 276-82.

27. Rathus JH, Miller AL. Dialectical behavior therapy adapted for suicidal adolescents. Suicide Life Threat Behav 2002; 32: 146-57.

28. Bateman A, Fonagy P. Treatment of borderline personality disorder with psychoanalytically oriented partial hospitalization: an 18 month follow-up. Am J Psychiatry 2001; 158: 36-42.

29. Bateman AW, Fonagy P. Mentalization-based treatment of BPD. J Personal Disord 2004; 18: 36-51.

30. Bateman A, Fonagy P. Psychotherapy for borderline personality disorder: mentalization-based treatment. Oxford: Oxford University Press, 2004.

31. Bateman A, Fonagy P. Effectiveness of partial hospitalization in the treatment of borderline personality disorder: a randomized controlled trial. Am J Psychiatry 1999; 156: 1563-9.

32. Kåver A, Nilsonne A, Laberg S. Dialektisk atferdsterapi ved emosjonell ustabil personlighetsforstyrrelse. Oslo: Gyldendal akademisk, 2005.

33. Larsson B, Grøholt B, Mehlum L. Behandling vid upprepad självskada och suicidförsök hos tonåringar: en kontrollerad multicenterstudie. Suicidologi 2006; 11: 16-7. 